\title{
GESTÃO ESTRATÉGICA E AS COMPETENCIAS GERENCIAIS NO DEPARTAMENTO DE MARKETING: ESTUDO DE UMA INDÚSTRIA DE BEBIDAS
}

\author{
STRATEGIC MANAGEMENT AND THE \\ MANAGING COMPETENCES IN THE \\ MARKETING DEPARTMENT: A STUDY IN A \\ BEVERAGE INDUSTRY
}

Recebido 21/10/2012 Aceito 21/01/2013

Lindiane da Veiga Baisch ${ }^{1}$ Rolando Juan Soliz Estrada ${ }^{2}$

Flávia Luciane Scherer ${ }^{3}$ Ivanete Schneider Hahn ${ }^{4}$ Bruno Da Veiga Thurner ${ }^{5}$

\section{RESUMO}

O presente trabalho apresenta um estudo de caso de uma indústria de bebidas, localizada no município de Santa Maria/RS, que utiliza o planejamento estratégico em suas atividades. O objetivo desta pesquisa é identificar as competências gerenciais do gerente de marketing da empresa em estudo. Para atingir este objetivo, estudou-se o Modelo Estrada (2007) de gestão estratégica, analisou-se o planejamento estratégico e também as competências, presentes e esperadas do gerente de marketing da empresa em questão. A coleta dos dados ocorreu por meio de levantamento documental, e aplicou-se uma entrevista semiestruturada junto ao gerente de marketing, seu superior direto e seus subordinados. Com essas entrevistas, foi possível fazer a análise das competências gerenciais que esse profissional apresenta e as que deveria apresentar, para o eficiente desempenho de suas funções e a otimização da gestão estratégica da empresa.

Palavras-chave: Gestão Estratégica; Planejamento Estratégico; Competências Gerenciais

\footnotetext{
${ }^{1}$ Mestre em Engenharia da Produção pela Universidade Federal de Santa Maria. Santa Maria, Rio Grande do Sul, Brasil. E-mail: Ibaisch@cvism.com.br

2 Doutor em Engenharia de Produção pela Universidade Federal de Santa Catarina e Pós-Doutorado em Administração pela Universidade de São Paulo - USP. Professor da Universidade Federal de Santa Maria. Santa Maria, Rio Grande do Sul, Brasil. E-mail: rolando@smail.ufsm.br

${ }^{3}$ Doutora em Administração pela Universidade Federal de Minas Gerais (UFMG). Professora do Departamento de Ciências Administrativas e Coordenadora do Curso de Mestrado Profissional em Gestão de Organizações Públicas da Universidade Federal de Santa Maria (UFSM). Santa Maria, Rio Grande do Sul, Brasil. E-mail: flaviascherer@globo.com

${ }^{4}$ Mestranda em Administração pela Universidade Federal de Santa Maria (UFSM). Santa Maria, Rio Grande do Sul, Brasil. E-mail: ivischneider@hotmail.com

${ }^{5}$ Graduação em Desenho Industrial pela Universidade Federal de Santa Maria (UFSM). Diretor do Estudio Morph. Santa Maria, Rio Grande do Sul, Brasil. E-mail: bruno@estudiomorph.com
} 


\section{ABSTRACT}

This work presents the study in a beverage industry, in the city of Santa Maria in the state of Rio Grande do Sul, Brazil, that uses strategic planning in its activities. The research aimed to identify the managing competences of the marketing manager at the studied company. In order to achieve this goal, we studied the Estrada (2007) strategic management model, where we analyzed the present and expected roles and the competences of the marketing manager. In order to collect data, we applied a semi structured interview to the marketing manager, his/her boss and his/her subordinates. We analyze the managing competences that this professional has and should have, for an efficient performs at its functions and the optimization of the company strategic management.

Keywords: Strategic Management; Strategic Planning; Management Competences

\section{INTRODUÇÃO}

As organizações, em um período de concorrência acirrada, constantes inovações, em, que as mudanças ocorrem de forma acelerada, buscam, constantemente, novas estratégias e ferramentas, visando a diferenciarem-se dos concorrentes e atenderem as necessidades dos clientes, para assim alcançarem os objetivos almejados. Dessa forma, a empresa aumenta suas chances de se manter no mercado ao qual está inserida e também, aufere melhores condições de enfrentar seus concorrentes. Isso traduz a intensa necessidade de formular estratégias proativas e de impacto, de modo a impulsionar a empresa, independentemente do setor de atuação, ao maior êxito possível.

Da mesma forma que as empresas estão enfrentando dificuldades, os indivíduos encontram-se submetidos a mudanças constantes em seu ambiente, em seus objetivos, em sua forma de atuar, em suas expectativas. Por isso, veem-se obrigados a refletir sobre o caminho a abordar no futuro, sendo compelidos a planejar.

Sendo assim, o planejamento estratégico é uma ferramenta que contribui com a organização, no sentido de pensar antecipadamente não apenas as ações que devem ser tomadas, mas também a sua missão, a sua visão, os seus objetivos, as estratégias e os programas individuais. Aliadas ao planejamento estratégico, encontram-se as pessoas, com as competências essenciais dos seus gestores que se fazem necessárias para adequarem e sustentarem essa gestão, de acordo com as funções desenvolvidas em cada área. Com isso, é possível implementar o plano com êxito, tornando-o um potencial diferencial e competitivo para as organizações.

Essas mudanças, que permanecem e se tornam mais intensas nos dias atuais, exigem das organizações: flexibilidade - por meio da maleabilidade nos processos de trabalho; agilidade - por meio da velocidade nas mudanças; geração de conhecimento - por meio do processo de aprendizagem organizacional; criação de capital intelectual - por meio do desenvolvimento de capacidades individuais e do comprometimento dos colaboradores; e, nova forma de pensar a organização - por meio de uma visão sistêmica e não segmentada em suas partes componentes (ULRICH, 2000). Assim, organizações que estão inseridas nessa configuração, praticando essas dimensões, expõem maior capacidade para apresentar níveis de excelência de desempenho individual e organizacional e, consequentemente, maior vantagem competitiva. Com isso, a complexidade do mercado, aliada à globalização, exige dos profissionais de marketing, cada vez mais, conhecimentos dos ambientes interno e externo da empresa e criatividade de adequarem-se às novas modalidades de gestão.

Destarte, para o profissional de marketing estar integrado, alinhado e comprometido com os objetivos da empresa, deve apresentar as competências compatíveis a sua área de atu- 
ação, ou seja, seus conhecimentos, habilidades e atitudes precisam estar alinhados às funções que desempenha em seu departamento, para gerar resultados satisfatórios, como a otimização da gestão estratégica.

\subsection{Justificativa}

As mudanças ocorridas no ambiente organizacional estão levando à formação de um novo perfil profissional. Com isso, passou-se a exigir dos profissionais conhecimentos e aptidões diferenciadas, para a atuação neste cenário atual dos negócios. Nesse sentido, as organizações precisam planejar, e esse profissional necessita ter vistas para o futuro, alinhando suas ações e suas práticas a uma força condutora comum, e orientar o presente pelo futuro, não pelo passado. Ao mesmo tempo, a organização deve permitir uma adequada previsão de investimento e a garantia de competitividade, da mesma maneira que as pessoas devem planejar para comunicar ações e objetivos para sua vida.

A empresa competitiva precisa compreender o elemento humano e desenvolver a educação corporativa, o que trará implicações mais concretas para a organização. Assim, a tarefa de administrar exige, muitas vezes, a flexibilização de conceitos, procedimentos e comportamentos, pois é uma tarefa sempre repleta de conteúdo humano e social. Segundo Porter (1991), a gestão estratégica preocupa-se com a construção não de modelos, mas de estruturas conceituais, que identificam as variáveis relevantes para analisar as questões a serem feitas para perseguir o sucesso.

De forma mais geral, Hamel e Prahalad (1990) introduziram o conceito de competências essenciais como base da vantagem competitiva, conceituando competências essenciais como conhecimento coletivo de uma organização, para coordenar diversas habilidades produtivas e integrar várias tecnologias. Os mesmos autores explicam que as competências essenciais não diminuem com o uso, ao contrário dos ativos físicos, que se deterioram com o tempo, as competências são reforçadas de acordo com o seu uso e compartilhamento. Para construir e manter a liderança em longo prazo, a empresa terá que ser vencedora não só em competências essenciais, mas também em produtos essenciais e produtos finais.

As competências terão que ser desenvolvidas no nível corporativo, evitando as restrições impostas pelas unidades de negócios. Uma competência essencial é um conjunto de habilidades e tecnologias, e não uma única habilidade ou tecnologia. Representa a soma do aprendizado de todos os conjuntos de habilidades da empresa, tanto no nível pessoal como organizacional. Por conseguinte, dificilmente estará baseada em um único indivíduo ou em uma pequena equipe. Sabe-se que muitas empresas, ao implementarem o planejamento estratégico, não atingem os resultados almejados. Nesse contexto, surge a necessidade de um estudo aprofundado a respeito da seguinte demanda: quais são as competências necessárias para os gestores no departamento de marketing, e que otimizem a gestão estratégica?

Destarte, o presente estudo objetiva listar e analisar as competências necessárias ao gestor de marketing para a otimização da gestão estratégica da organização, em face as exigências do mercado globalizado, destacando os principais atributos que esse executivo deve apresentar. Como objetivos secundários, intui-se estudar o Modelo Estrada (2007) de Gestão Estratégica, analisar o planejamento estratégico da empresa, e identificar as competências presentes e esperadas do gerente de marketing da empresa em estudo.

Este artigo está subdividido em cinco partes. A primeira parte apresenta uma visão geral do trabalho, sua importância e seus objetivos. A segunda parte expõe a revisão de literatura que serviu de base para a pesquisa. A terceira seção aborda a metodologia utilizada, detalhando o 
tipo de estudo e os meios empregados para coleta e análise dos dados. A quarta parte refere-se aos resultados da pesquisa. Por fim, a quinta parte compreende as considerações, recomendações e sugestões para estudos futuros.

\section{FUNDAMENTAÇÃO TEÓRICA}

Nesta seção, apresenta-se a revisão de literatura que serviu de base para a pesquisa. As referências teóricas utilizadas como base para o desenvolvimento do trabalho proposto relacionamse aos seguintes assuntos: planejamento estratégico, competências gerenciais, alinhamento entre competências individuais, organizacionais e resultados, e competências do gerente de marketing.

Esses referenciais sustentarão a pesquisa, a fim de que se compreenda que é de suma importância alocar as pessoas, com suas características individuais, nos cargos condizentes com suas competências visando, com isso, a evidenciar que a otimização da gestão estratégica está diretamente relacionada com o alinhamento entre pessoas, funções e competências.

\subsection{Gestão Estratégica}

A história dos negócios é uma sucessão de novos desafios, problemas e oportunidades.

À medida que novos fatos vão surgindo, os administradores mais engenhosos experimentam continuamente novas respostas. Algumas delas fracassam, mas outras são bem sucedidas. Estas últimas são conhecidas como boas práticas. As empresas não devem apenas se reposicionar quanto aos negócios, mas também devem ser capazes de suportar o impacto cruzado e a interdependência da sociedade mais ampla. A atenção deve deslocar-se do modelo competitivo para o modelo empreendedor, mas este último deve ter objetivos muito mais amplos aos que teve na história passada. É devido à necessidade dessa reorientação, por vezes drástica, que esta se denomina "a era da descontinuidade".

O planejamento estratégico, quando aplicado a unidades e indivíduos, possibilita que o pensamento estratégico não fique restrito à organização como um todo, mas desça de forma integrada, em seus vários níveis, até o profissional, o que torna mais fácil a implementação do plano estratégico, inclusive no caso da organização em sua totalidade.

Na prática, é preciso saber dirigir os esforços para aquilo que traz resultado, pois não se obtém resultado apenas por ser esforçado. As pessoas são eficientes ao desenvolverem bem um processo e eficazes ao alcançarem bons resultados. O responsável por uma unidade não pode deixar de ser eficiente, mas tem que contribuir para o melhor resultado de toda a empresa. Ser eficiente é desenvolver bem sua obrigação, mas ser eficaz é o que traz o sucesso para a empresa.

O processo de implementação de estratégia é o total geral das atividades e escolhas necessárias para a execução de um plano estratégico. É um processo onde as estratégias e políticas são postas em prática, com o desenvolvimento de programas, orçamentos e procedimentos. 0 processo de inserção é a parte-chave da gestão estratégica e depende, claramente, dos responsáveis pelo processo.

Conforme a organização estiver estruturada, aqueles que implantam a estratégia provavelmente constituirão um grupo muito mais diverso de pessoas do que aqueles que a formulam. Na maioria das corporações, todos os que trabalham na organização devem ser considerados implementadores da gestão estratégica. Assim, cada gerente operacional, supervisor de linha e funcionário estarão, de alguma maneira, envolvidos na implementação de estratégias corporativas, de negócios e funcionais. Destarte, a relação com as competências gerenciais é clara no processo de implantação da estratégia na organização. 


\subsection{Planejamento Estratégico}

Para Almeida (2001), planejamento estratégico é uma técnica administrativa que, por meio da análise do ambiente de uma organização, cria a consciência de suas oportunidades e ameaças, dos seus pontos fortes e fracos, para o cumprimento da sua missão e, por meio dessa consciência, procura estabelecer o propósito de direção que a organização deverá seguir para aproveitar as oportunidades e evitar riscos.

De acordo com Ansoff (1981) e Almeida (2003), o planejamento estratégico é um processo sistemático para tomada de decisões. Não pretende adivinhar o futuro, mas, sim, garantir o sucesso da empresa em seu ambiente, evitando o máximo de surpresas. Encontram-se, na literatura, diversos modelos de gestão estratégica que apresentam características distintas. Este trabalho segue o proposto pelo Modelo de Estrada (2007), elaborado na Universidade Federal de Santa Maria, pelo Núcleo de Gestão Empresarial.

O Modelo Estrada (2007) é composto de quatro etapas: avaliação, formulação, implementação e aprendizagem - que estão relacionadas e interagem entre si por meio do processo de mudança e pelo monitoramento e retroalimentação, conforme a figura 1.

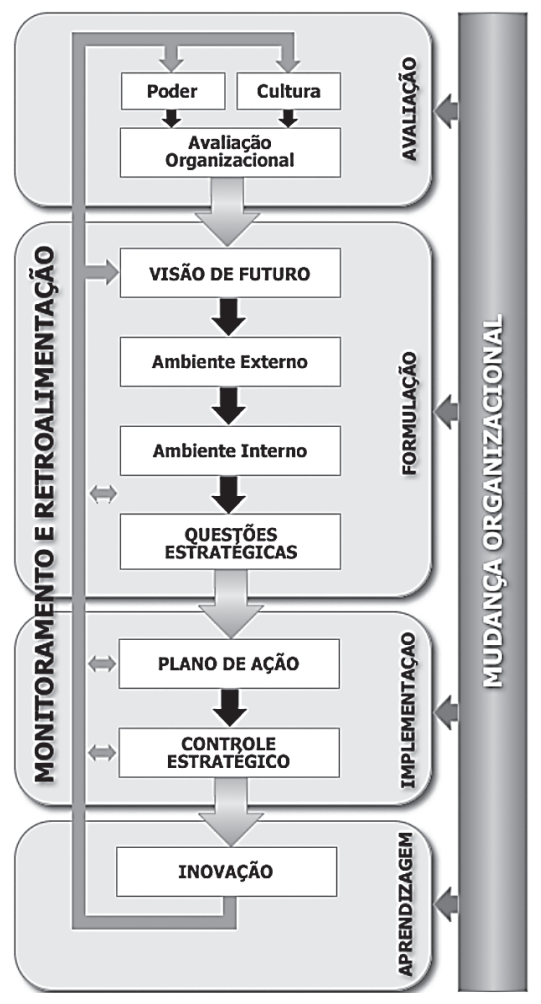

Figura 1 - Modelo de planejamento estratégico de Estrada Fonte: Estrada (2007, p.157).

Para a melhor compreensão da organização, o Modelo de Estrada (2007) enfatiza a prévia elaboração, permitindo realizar uma avaliação da personalidade da organização, a sua cultura e as suas relações de poder, assim como uma avaliação de posição que contemple os pilares que a sustentem: crescimento lucrativo, mercados, imagem, comunidade e governo, processos internos, pessoas e aprendizado.

O modelo proposto apresenta, em sua fase de avaliação, a etapa pré-operacional, pres- 
supondo que, para a elaboração, implementação e controle do plano estratégico, inicialmente devem ser levantados os aspectos qualitativos e quantitativos da organização, ou seja, a personalidade e a posição da organização, da cultura e o poder e da situação em relação aos pilares.

A avaliação é desenvolvida com o objetivo de levantar e definir as possibilidades e as condições de inserção do modelo de gestão estratégica. Essa etapa divide-se em outras três: análise sobre o poder, análise sobre a cultura, e avaliação organizacional. Na etapa da formação estratégica, realiza-se o delineamento da visão de futuro que a empresa pretenda alcançar, assim como uma avaliação do ambiente externo, por meio de cenários, levantando as oportunidades e ameaças. Também são levantados os pontos fortes e fracos da empresa. Essa etapa inicia pela definição da visão de futuro da empresa, ou seja, a determinação dos propósitos globais permanentes que sirvam como base para a realização do planejamento estratégico.

A visão é inspiração para o futuro almejado, não é limitada por tempo. Representa propósitos globais permanentes, serve como base para o planejamento estratégico. Um futuro ideal para a organização é delineado por uma visão tanto no que se refere à ação no ambiente externo quanto em relação às condições do ambiente interno. A visão de futuro representa a inspiração de ideal a ser alcançado pela empresa. Essa visão apresenta três componentes básicos: valores, finalidade e supermetas.

Os valores são os preceitos essenciais e permanentes de uma organização, são princípios de orientação perenes - valores essenciais não mudam, devem resistir ao tempo e têm importância intrínseca para o pessoal interno da organização, sendo que apenas alguns são verdadeiramente essenciais. A finalidade representa a razão de ser da organização, reflete as motivações idealistas das pessoas, para impulsionar o funcionamento da empresa. Não se limita a descrever os objetivos da empresa, em termos de produtos e clientes, ela capta a alma da organização. As supermetas têm a função de focar e unificar os esforços da organização e atuam como catalisadoras do espírito de equipe.

$\mathrm{Na}$ implementação, realiza-se o controle das questões estratégicas por meio do plano de ação. Também é realizado o controle estratégico por meio do plano orçamentário e de indicadores de desempenho, que servirá de orientação para avaliar se a empresa está caminhando para o alcance de sua visão de futuro ou se necessitará de correção de rumo.

As questões estratégicas, segundo Estrada (2007), devem ser transformadas em planos de ação, os quais terão um detalhamento minucioso, para controle e monitoramento de seus resultados. A partir dessa ideia, o plano de ação deverá especificar a questão estratégica a que pertença o plano de ação, a data em que será iniciada e a previsão de sua conclusão, os responsáveis pela execução e gerenciamento dos resultados no decorrer de sua execução. Também deve apresentar o grupo de pessoas que estará executando o plano, o orçamento necessário à sua execução, e qual o indicador de controle que será monitorado e controlado regularmente, para que se possa determinar os resultados, com modificações, alterações desse plano, ou, ainda, a definição de novas ações estratégicas para garantir o que foi proposto na visão de futuro.

A última fase considerada, a aprendizagem, levará ao processo de inovação, pela absorção do crescimento técnico e comportamental da organização e de seus recursos humanos, ocorridos durante a mudança organizacional. Essa fase é sustentada pelo monitoramento e retroalimentação de todas as etapas anteriores e, portanto, consiste em uma verificação atenta e minuciosa da regularidade de cada uma das etapas anteriores, para que a empresa possa monitorar todas as atividades estabelecidas no planejamento estratégico, de forma a garantir que estejam sendo realizadas conforme o planejado e corrigir qualquer desvio importante.

Os modelos e abordagens de planejamento estratégico, apresentados anteriormente, não se excluem. Cada um deles responde a uma faceta particular dos problemas administrati- 
vos, e seu desenvolvimento apresenta uma sequência lógica. No entanto, implementação de uma gestão estratégica eficiente e, ao mesmo tempo, eficaz depende diretamente da estrutura organizacional e das competências dos gestores dentro dessa estrutura. As pessoas precisam estar alinhadas com as metas e objetivos da empresa, tendo competências compatíveis com as funções que desempenham, para o sucesso da gestão estratégica da organização.

\subsection{Competências gerenciais}

O mercado vem sofrendo diversas turbulências e modificações. Juntamente à revolução tecnológica, a intensificação dos processos de globalização, a competitividade e as profundas transformações nas estruturas dos mercados provocaram fortes pressões nas organizações. A concorrência se tornou uma característica comum do mercado, obrigando as empresas a reverem seus modelos e instrumentos de gestão, principalmente os direcionados ao gerenciamento de pessoas.

A competitividade faz com que as competências essenciais, empresariais e humanas, sejam prioritárias. Competências estas, que podem ser adquiridas através da educação e treinamento e com o talento individual da pessoa. Pessoas competentes são as que satisfazem os requisitos atuais, envolvendo habilidades técnicas, política e comportamentais, conseguem resultados, compartilham valores, planejam, lideram, organizam e controlam suas atividades. Na busca da eficácia operacional, muitas empresas privadas têm focado nas pessoas como a chave do sucesso.

O processo de gestão estratégica de competências visa a aproximar os objetivos organizacionais e os pessoais (profissionais). A partir dessa premissa, fica mais fácil de compreender os dois principais níveis de competências: organizacional e pessoal. No primeiro nível, incluem-se as core competences, ou as competências essenciais da organização, que são responsáveis pela atuação da empresa no mercado, estimulando a construção de um diferencial competitivo, baseado na(s) especialidade(s) e especificidade(s) de cada organização.

No segundo nível, as competências das pessoas, observa-se a necessidade crescente em formar e valorizar o profissional que possa oferecer respostas mais rápidas às demandas do mercado e da empresa, que tenha uma postura aberta à inovação, baseado num perfil criativo e flexível, que esteja preparado para trabalhar e estimular o desenvolvimento das outras pessoas com quem trabalha (HAMEL \& PRAHALAD, 1994).

Analisando esse tema sob outra ótica, verifica-se que a aprendizagem da iniciativa ocorre por meio da intersecção de três elementos, considerados formadores das competências: 1 ) saber: relacionado ao conhecimento; 2) saber fazer: corresponde às habilidades e 3) saber agir: vinculado a atitudes (RABAGLIO, 2001).

Os conhecimentos, habilidade e atitudes complementam-se e se articulam de forma sistêmica. Uma prática organizacional, que priorize apenas um desses níveis, subestima o efeito dos demais. $O$ desenvolvimento de competências procura o equilíbrio entre o saber, o saber-fazer e o saber-agir. Essa visão descreve o processo de aprendizagem no cruzamento entre o que o individuo conhece, o que pratica, e como se comporta no cenário organizacional.

Os elementos que se destacam no desenvolvimento de competências podem ser sintetizados por meio da verificação dos seguintes fatores: as competências estão associadas ao desenvolvimento de conceitos, habilidades e atitudes, demandam capacitação, e se traduzem na capacidade de mobilizar recursos em práticas de trabalho. Sendo assim, implicam articular recursos e servem de base para a busca de melhores desempenhos individuais, o que acarreta em um melhor resultado para a organização como um todo. 
Com isso, observa-se que determinadas práticas organizacionais podem incentivar o desenvolvimento de competências. O fato de a organização estar imersa em uma lógica por competências sugere que missão, visão, valores e cultura são dinâmicos e refletem um posicionamento da empresa no mercado. A competitividade da organização depende do potencial de desenvolvimento de processos e pessoas. Os conhecimentos, habilidades e capacidades constituem-se requisitos para que a empresa tenha a sua vantagem competitiva. Por fim, a aprendizagem coletiva e organizacional alavanca os processos de mudança.

Portanto, estabelecer o direcionamento estratégico, alinhando a competências organizacionais e desdobrando em competências tanto coletivas como individuais, implica refletir sobre a cultura organizacional e o modelo de gestão.

\subsubsection{Competências Individuais}

Partindo-se da ideia de Rabaglio (2001), competência significa o conjunto de qualificações que permite que uma pessoa apresente desempenho superior em um trabalho ou uma situação. Essas competências podem ser previstas e estruturadas de modo a estabelecer um conjunto ideal de qualificações necessárias para que a pessoa possa atingir o nível de desempenho desejado para maximizar os resultados da empresa.

Nessa linha, Parry (1996) desenvolveu o conceito de competência como um agrupamento de conhecimentos, habilidades e atitudes correlacionados, que afetam parte considerável da atividade de alguém, a qual se relaciona com o desempenho, que pode ser medido segundo padrões pré-estabelecidos e que pode ser melhorado por meio de treinamento e desenvolvimento.

Mesmo existindo muitos conceitos diferentes, competência pode ser definida, de forma simplificada, como o agrupamento de conhecimentos, habilidades e atitudes específicas, que fazem com que a pessoa desempenhe, com eficácia, suas atividades, em qualquer situação imposta. Essas competências representam o diferencial competitivo das organizações e também podem ser caracterizadas como um importante instrumento para processos de seleção de pessoal.

Nesse contexto, podem-se evidenciar alguns elementos que constituem as competências individuais. Rabaglio (2001) divide o perfil de competências pessoais em competências técnicas e comportamentais. As competências técnicas são basicamente pré-requisitos vinculados ao cargo ocupado pela pessoa. Têm-se, portanto, conhecimentos e habilidades específicas para a realização de suas atividades e funções específicas. $O$ grande diferencial e desafio para os próprios indivíduos, e para a empresa, está em desenvolver competências comportamentais, como flexibilidade, criatividade, inovação e empreendedorismo. As competências comportamentais, conforme o quadro 1, estão relacionadas a atitudes e comportamentos compatíveis com as atribuições a serem desempenhadas.

\begin{tabular}{|c|l|l|}
\hline \multicolumn{1}{|c|}{ Conhecimentos (C) } & \multicolumn{1}{|c|}{ Habilidades (H) } & \multicolumn{1}{c|}{ Atitudes (A) } \\
\hline \multicolumn{1}{|c|}{ Saber } & \multicolumn{1}{|c|}{ Saber fazer } & \multicolumn{1}{c|}{ Querer fazer } \\
\hline $\begin{array}{l}\text { Conhecimentos técnicos, específi- } \\
\text { cos, escolaridade, cursos e espe-- } \\
\text { cializações. }\end{array}$ & $\begin{array}{l}\text { Experiência prática, domínio nos } \\
\text { conhecimentos técnicos. } \\
\text { Implica ter praticado o conheci- } \\
\text { mento. }\end{array}$ & $\begin{array}{l}\text { Ter atitudes compatíveis para } \\
\text { atingir eficácia em relação aos co- } \\
\text { nhecimentos e habilidades adqui- } \\
\text { ridos ou a serem adquiridos. }\end{array}$ \\
\hline
\end{tabular}

Quadro 1 - Competências pessoais

Fonte: Rabaglio (2001, p.6) 
Rabaglio (2001) cita, como principais exemplos de competências comportamentais, iniciativa, criatividade, habilidade de relacionamento interpessoal, comunicação verbal, liderança, negociação, empreendedorismo, espírito de equipe, bom humor, entusiasmo, espírito de servir, humildade, extroversão, persuasão, atenção a detalhes, participação, cooperação, facilidade de trabalhar com metas, foco em resultados, flexibilidade, empatia, agilidade, entre outros.

Os elementos que constituem as competências individuais são apresentados de diversas formas, podendo mostrar variações, dependendo do autor. Entretanto, há uma predominância em torno dos seguintes elementos que constituem a competência: conhecimentos, habilidades e atitudes. Dependendo da perspectiva de cada autor, cada um dos elementos poderá assumir um grau de importância maior em relação aos demais.

\subsection{Alinhamento entre competências individuais, organizacionais e resultados}

Segundo Leme (2005), competências é o conjunto de conhecimentos, habilidades e atitudes que afetam a maior parte do trabalho de uma pessoa e que se relacionam com seu desempenho no trabalho. Nesse sentido, as pessoas vinculadas à empresa precisam trazer os resultados que a organização necessite e espere, mas, por sua vez, a organização também precisa dar condições de crescimento profissional ao indivíduo, para que ele alcance seus objetivos. Esse alinhamento fica evidenciado na figura 2 :

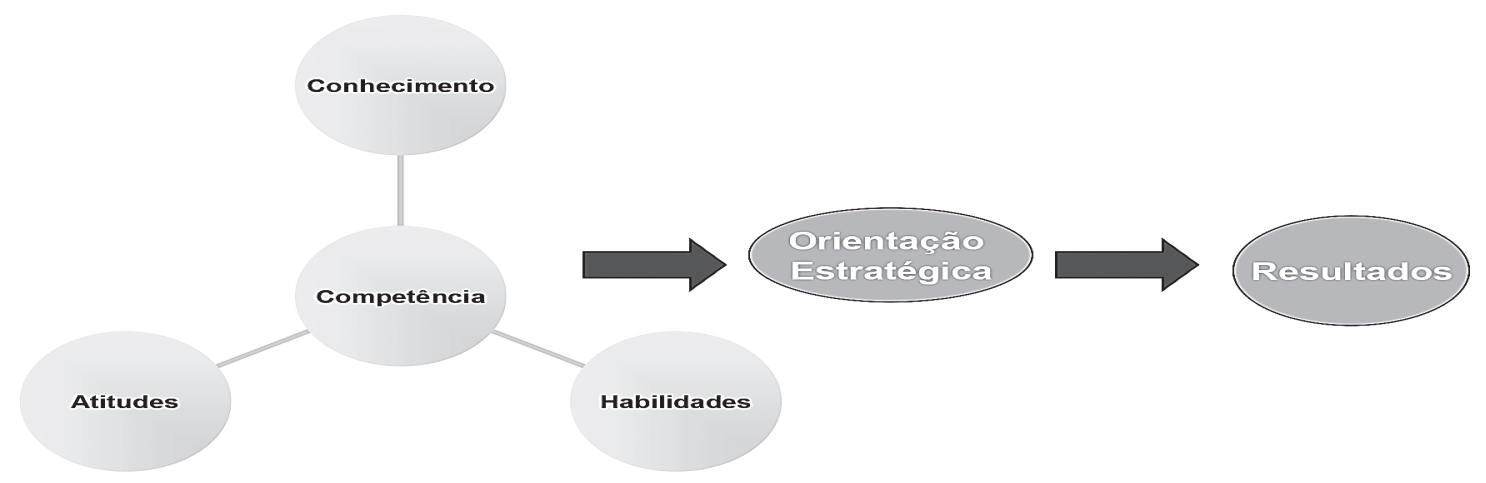

Figura 2 - Conceito de competências

Fonte: Estrada (2007)

Sendo assim, as pessoas adquirem conhecimentos por meio de estudos acadêmicos, cursos técnicos; transformam esses conhecimentos em habilidades por meio da prática e treinamento; e devem possuir postura e comportamento compatíveis com as atividades que desempenhem, podendo ser demonstrados por valores, crenças e princípios no ambiente de trabalho, para, com isso, alcançarem os resultados almejados.

Nesse sentido, as competências são a conjugação entre as características individuais e as qualidades requeridas para que uma atividade profissional seja bem executada. Segundo Fleury e Fleury (2001), competência deve agregar valor em duas dimensões: valor econômico para a organização e valor social para o indivíduo. Para os mesmos autores, competência significa saber agir de forma responsável, que implica mobilizar, integrar, transferir conhecimentos, recursos e habilidades.

Além dessas competências, a capacidade de gerar resultados é de extrema importância. Analisando-se essas associações de ideias, fica fácil perceber a necessidade de intera- 
ção entre competências individuais e organizacionais para a eficácia organizacional. O desenvolvimento de competências pessoais possibilita que as práticas organizacionais sejam direcionadas para uma gestão mais efetiva, compatível à estratégia competitiva da empresa.

Nesse sentido, a questão de atitudes mais apropriadas à nova realidade proposta é chave para o aprimoramento das práticas de trabalho e para o envolvimento de todas as pessoas da organização.

\subsection{Competências do gerente de marketing}

No entanto, as competências são primordiais para que a relação entre indivíduo e organização gere resultados satisfatórios para a empresa e também para o indivíduo. Além de interagir com as estratégias da organização, o profissional precisa ter conhecimentos, habilidades e atitudes compatíveis com as funções que desempenha. Ou seja, o perfil do profissional precisa estar alinhado ao perfil que a organização procura para o desempenho de funções específicas. O profissional de marketing, também conhecido como Chief Marketing Officer (CMO), segundo Sebrae (2006), é o profissional cuja atividade compreende, como caráter preponderante, a participação permanente e/ou poder de decisão em áreas estratégicas de marketing, assim considerados a criação e o desenvolvimento de estratégias de preço, distribuição, comunicação e promoção de quaisquer produtos ou serviços.

Destarte, as competências do gerente de marketing precisam estar alinhadas às funções que ele desempenha na organização. De acordo com Sebrae (2006), a atividade do profissional de marketing consiste em entender e modificar as atitudes e comportamentos dos consumidores, de forma a torná-las favoráveis aos objetivos da organização. Isso só é possível dentro de certos limites, devido às diferentes características individuais do consumidor. Os responsáveis pelo marketing das organizações devem esforçar-se para verem os consumidores como eles são de fato, e não como gostariam que fossem.

De acordo com Russell Reynolds Associates (2006), o CMO deve ter habilidades em geração de resultados e retorno sobre investimentos; desenvolver estratégias a partir da análise de clientes, comunicação, visão financeira e de negócios; vender focado no cliente a fim de demonstrar uma habilidade consistente em encontrar e superar as expectativas destes; desenvolver produtos, planejamento estratégico - desenvolvendo o alinhamento estratégico entre os objetivos da organização e as capacidades e oportunidades do mercado. E atitudes como liderança, empreendedorismo, perspectiva estratégica, adaptabilidade, flexibilidade, determinação, carisma, empatia e persuasão.

Considerando-se essas informações, podem-se separar conhecimentos, habilidades e atitudes do CMO de acordo com o conceito de competência, de Rabaglio (2001) e Gramigna (2002). Com isso, o quadro 2, relaciona as principais competências que o CMO deve apresentar na atualidade. 


\begin{tabular}{|l|l|l|}
\hline \multicolumn{1}{|c|}{ Conhecimentos (saber) } & \multicolumn{1}{|c|}{ Habilidades (saber fazer) } & \multicolumn{1}{c|}{ Atitudes (querer fazer) } \\
\hline - Graduação em Administração ou Co- & - Capacidade analítica & - Agilidade e dinamismo voltados \\
municação Social. & - Capacidade de lidar com incertezas & para resultados \\
- Pós-graduação em marketing & - Articulação/orientação para o cliente. & - Pró-ação e gestão de mudanças \\
- Programas de computador: Excel, & - Administração do tempo & - Criatividade \\
Acrobat, Photoshop... & - Coordenação de trabalhos em equipe & - Autodesenvolvimento \\
- Perfil generalista & - Capacidade para tratar com culturas & - Iniciativa e flexibilidade \\
- Conhecimentos de negócios nacio- & diversas & - Negociação \\
nais e internacionais & - Habilidades de negociação & - Predisposição para correr riscos \\
- Idiomas & - Planejamento estratégico (estrategis- & - Motivação \\
- Tecnologia de informação & ta) Resistência a frustração \\
- Cultura de outros países (vivência & - Capacidade de delegação & - Empreendedorismo \\
internacional) & - Capacidade de decisão & - Comportamento ético \\
- Experiência profissional na área de & - Habilidade interpessoal & - Autoconfiança \\
comercialização e marketing. & - Foco em resultados & - Abertura para novas ideias \\
- Técnicas de negociação e vendas & - Administrador de conflitos & - Integridade \\
- Conhecimento em publicidade e e & - Desenvolver pessoas & - Persuasão \\
propaganda & - Capacidade de viabilizar e implemen- & - Assertividade \\
& - Empatia \\
\hline
\end{tabular}

Quadro 2 - Competências do CMO

Fonte: Adaptado de Rabaglio (2001) e Gramigna (2002)

Sendo assim, o gerente do departamento de marketing de uma organização que apresente o conjunto de conhecimentos, habilidades e atitudes especificados anteriormente, ou a maioria deles, está norteado para os resultados esperados por sua atuação. Resultados, estes que, normalmente, são traçados no planejamento estratégico da empresa.

\section{MÉTODO}

Pode-se classificar este trabalho, quanto à natureza, como uma pesquisa qualitativa, pois busca a compreensão detalhada dos significados e das características situacionais apresentadas pelos entrevistados em uma indústria do setor de bebidas localizada na cidade de Santa Maria, região central do Rio Grande do Sul, onde o pesquisador atuou diretamente no seu ambiente, observando processos de trabalho, estudando documentos, entrevistando os envolvidos e participando da rotina da organização. Houve foco na observação em relação às competências do gerente de marketing e à otimização da gestão estratégica na estrutura organizacional do referido departamento.

A pesquisa caracteriza-se como descritiva, pois tem como objetivo a descrição das características da referida indústria do setor de bebidas, descrevendo o planejamento estratégico utilizado para alcance dos seus objetivos e as principais competências que o gerente de marketing possui e/ou deveria possuir para o sucesso na implementação desse planejamento.

A estratégia de estudo consiste em um estudo de caso, fazendo uma análise detalhada de uma indústria do setor de bebidas. Os dados foram coletados por meio de entrevistas semiabertas para os três níveis hierárquicos (avaliação $360^{\circ}$ ) relacionados à gerência de marketing. Obtiveram-se também informações por meio de pesquisa documental, referente à estrutura do departamento de marketing da empresa em estudo, às funções desempenhadas nessa estrutura e às competências gerenciais que o gerente de marketing possui e deveria possuir para a implementação da gestão estratégica.

A análise dos dados ocorreu por meio de tabulação destes, que originaram quadros e estatísticas descritivas. 


\section{RESULTADOS}

Esta seção apresenta os resultados da pesquisa, apresentando breves informações sobre a empresa estudada - o seu planejamento estratégico, a estrutura organizacional do departamento de marketing -, juntamente com a análise das competências do gerente deste departamento, visando à otimização da gestão estratégica da empresa.

A empresa objeto desta pesquisa atua no mercado de bebidas desde 1940. Após uma longa trajetória com a indústria de bebidas, e um lento processo de negociação, conseguiram a franquia de uma importante marca de bebidas mundial.

O grupo possui sua sede na cidade de Santa Maria, no centro do Estado do Rio Grande do Sul. A cidade foi escolhida por uma questão estratégica: sua posição geográfica privilegiada, a construção da primeira Universidade do interior do Brasil, e o grande número de pessoas que já formavam sua população.

$\mathrm{Na}$ atualidade, a empresa atende toda a região central, a fronteira oeste e o planalto médio do Rio Grande do Sul. Isso equivale a 25,3\% da população do Estado, em uma área de 94.892 $\mathrm{km}^{2}$ (o que corresponde a 44,9\% da área do Rio Grande do Sul), sendo 189 cidades, aproximadamente nove mil clientes diretos, vinte mil pontos de vendas e 2,5 milhões de consumidores.

\subsection{Gestão Estratégica da Empresa}

A empresa em questão definiu seu planejamento estratégico baseado no modelo Estrada (2007). Na fase de formulação estratégica, realizou-se: o delineamento da visão de futuro que a empresa pretende alcançar, uma avaliação do ambiente externo, por meio de cenários, levantando as oportunidades e ameaças, avaliação dos pontos fortes e fracos em relação ao ambiente interno. A partir dessas informações, são levantadas as questões consideradas indispensáveis e estratégicas para a concretização da visão de futuro.

Assim, para que haja o comprometimento das pessoas com a visão, é necessário que a visão organizacional esteja alinhada com a visão pessoal dos envolvidos, bem como que tenha clareza, seja coerente, convincente, compartilhada e tenha entusiasmo para gerar comprometimento das pessoas. Nesse contexto, a empresa redefiniu sua visão como:

Seremos reconhecidos como a melhor opção de bebidas, em qualquer lugar, a qualquer hora, na área de atuação, valorizando a SIMPLICIDADE, disseminando a TRANSPARÊNCIA e estimulando o compromisso com a INOVAÇÃO, CRIATIVIDADE e LIDERANÇA DE RESULTADOS.

O levantamento das questões estratégicas evidencia a necessidade de analisarem-se as competências do gerente de marketing.

\subsection{Competências do gerente de marketing da empresa}

O gerente de marketing da empresa apresenta competências essenciais para o desempenho de suas funções. Sendo o foco da pesquisa as competências desse gerente, relacionadas ao departamento de marketing. Em seguida, apresenta-se a descrição e análise dos conhecimentos, habilidades e atitudes que ele tem, deveria ter, e não tem (mas deveria ter) nessa área de atuação. Para isso, considerou-se o seu ponto de vista, o ponto de vista do diretor de operações e dos seus subordinados. 
O gerente de marketing apresenta conhecimentos importantes para o desempenho de suas funções na área que atua. A seguir, serão analisados os conhecimentos que esse gerente tem e os que deveria ter, para a eficiência no desempenho de suas funções, de acordo com os entrevistados. Os conhecimentos que o gerente de marketing apresentai, em ordem crescente de importância, estão relacionados no quadro 3.

\begin{tabular}{|l|l|l|}
\hline \multicolumn{1}{|c|}{ Diretor de Operações } & \multicolumn{1}{c|}{ Gerente de Marketing } & \multicolumn{1}{c|}{ Subordinados do Gerente } \\
\hline Marketing e comunicação & Gestão de pessoas & Marketing e comunicação \\
\hline Planejamento estratégico & Marketing e comunicação & Planejamento estratégico \\
\hline Administração de empresas & Gestão estratégica & Administração de empresas \\
\hline Gestão estratégica & Administração de empresas & Gestão de pessoas \\
\hline Gestão de pessoas & Técnicas de negociação & Gestão estratégica \\
\hline Técnicas de negociação & Planejamento estratégico & Técnicas de negociação \\
\hline Técnicas de liderança & Técnicas de liderança & Técnicas de liderança \\
\hline Contabilidade gerencial & Língua Inglesa & Contabilidade gerencial \\
\hline Língua Inglesa & Contabilidade gerencial & Língua Inglesa \\
\hline Sistemas de informação & Sistemas de informação & Sistemas de informação \\
\hline
\end{tabular}

Quadro 3 - Conhecimentos que o gerente de marketing atualmente apresenta

Analisando-se o quadro acima, é possível verificar que o gerente de marketing apresenta conhecimentos necessários para o eficiente desempenho de suas funções. No entanto, cabe ressaltar o alinhamento entre o diretor de operação e os subordinados do gerente de marketing, sobre o grau de importância dos conhecimentos que este gerente possui.

\subsection{Conhecimentos que o gerente de marketing deveria apresentar}

O quadro 4 relaciona os principais conhecimentos que o gerente de marketing da empresa deveria apresentar para o desempenho de suas funções, citados pelos entrevistados.

\begin{tabular}{|l|l|l|}
\hline \multicolumn{1}{|c|}{ Diretor de Operações } & \multicolumn{1}{c|}{ Gerente de Marketing } & \multicolumn{1}{c|}{ Subordinados do Gerente } \\
\hline Marketing e comunicação & Marketing e comunicação & Marketing e comunicação \\
\hline Gestão de pessoas & Gestão de pessoas & Técnicas de negociação \\
\hline Planejamento estratégico & Planejamento estratégico & Gestão estratégica \\
\hline Gestão estratégica & Gestão estratégica & Gestão de pessoas \\
\hline Técnicas de negociação & Administração de empresas & Planejamento estratégico \\
\hline Administração de empresas & Técnicas de negociação & Administração de empresas \\
\hline Técnicas de liderança & Técnicas de liderança & Legislação tributária \\
\hline Economia & Sistemas de informação & Economia \\
\hline Legislação tributária & Legislação tributária & Técnicas de liderança \\
\hline Sistemas de informação & Economia & Sistemas de informação \\
\hline
\end{tabular}

Quadro 4 - Conhecimentos que o gerente de marketing deveria apresentar

Nesse aspecto, é evidente o alinhamento entre o gerente de marketing e o seu superior, sobre os conhecimentos que esse cargo exige, ressaltando que o conhecimento em legislação tributária e em economia foi citado pela maioria dos entrevistados como sendo um conhecimento que esse gerente deveria apresentar, mas atualmente não apresenta. Fato este que deve ser levado em consideração a fim de aprimorar os conhecimentos para exercer esta função. 


\subsection{Habilidades que o gerente de marketing apresenta atualmente}

Além de apresentar conhecimentos relacionados à sua área de atuação, o gerente de marketing precisa ter habilidade na execução das suas tarefas. Nesse sentido, segue a análise das habilidades que o gerente de marketing apresenta atualmente e as que este deveria apresentar. $O$ gerente de marketing da empresa tem importantes habilidades para o eficiente desempenho de suas funções. O quadro 5 relaciona as dez principais habilidades desse gerente, em ordem crescente de importância para os entrevistados.

\begin{tabular}{|l|l|l|}
\hline \multicolumn{1}{|c|}{ Diretor de Operaçães } & \multicolumn{1}{c|}{ Gerente de Marketing } & \multicolumn{1}{c|}{ Subordinados do Gerente } \\
\hline Visão sistêmica & Relacionamento interpessoal & Visão de mercado e negócio \\
\hline Visão de mercado e negócio & Flexibilidade & Relacionamento interpessoal \\
\hline Relacionamento interpessoal & Liderança & Gestão de conflitos \\
\hline Flexibilidade & Implementação de novas ideias & Incentivo e pró-atividade \\
\hline Liderança & Gestão de conflitos & Flexibilidade \\
\hline Implementação de novas ideias & Persuasão & Liderança \\
\hline Persuasão & Incentivo e pró-atividade & Visão Sistêmica \\
\hline Incentivo e pró-atividade & Trabalhar sob pressão & Persuasão \\
\hline Gestão de conflitos & Visão de mercado e negócio & Trabalhar sob pressão \\
\hline Trabalhar sob pressão & Visão sistêmica & Implementação de novas ideias \\
\hline
\end{tabular}

Quadro 5 - Habilidades que o gerente de marketing apresenta

Analisando-se o quadro acima, é possível constatar que o gerente de marketing apresenta importantes habilidades para o eficiente desempenho de suas funções. No entanto, cada entrevistado tem diferentes opiniões sobre o grau de importância das mesmas.

\subsection{Habilidades que o gerente de marketing deveria apresentar}

As dez principais habilidades, que o gerente de marketing deveria apresentar, em ordem crescente de importância, estão relacionadas no quadro 6 , segundo as respostas dos entrevistados:

\begin{tabular}{|l|l|l|}
\hline \multicolumn{1}{|c|}{ Diretor de Operações } & \multicolumn{1}{c|}{ Gerente de Marketing } & \multicolumn{1}{c|}{ Subordinados do Gerente } \\
\hline Visão sistêmica & Visão sistêmica & Flexibilidade \\
\hline Persuasão & Flexibilidade & Tomada de decisão \\
\hline Incentivo e pró-atividade & Liderança & Trabalhar sob pressão \\
\hline Flexibilidade & Implementação de novas ideias & Incentivo e pró-atividade \\
\hline Língua estrangeira & Gestão de conflitos & Negociação \\
\hline Gestão de conflitos & Persuasão & Língua estrangeira \\
\hline Trabalhar sob pressão & Incentivo e pró-atividade & Visão sistêmica \\
\hline Finanças & Relacionamento interpessoal & Finanças \\
\hline Negociação & Finanças & Gestão de conflitos \\
\hline Tomada de decisão & Língua estrangeira & Persuasão \\
\hline
\end{tabular}

Quadro 6 - Habilidades que o gerente de marketing deveria apresentar

O diretor de operações e também a maioria dos subordinados do gerente de marketing citam que as habilidades em língua estrangeira, finanças, negociação e tomada de decisão são relevantes para o desempenho desta função, aspectos estes que não foram citados pelos entrevistados como sendo habilidades que o gerente apresenta. Sendo assim, ressalta-se a im- 
portância em dominar esses pontos para, com isso, desempenhar ainda melhor suas atividades. Para o gerente de marketing, além das habilidades que ele já apresenta, apenas finanças e língua estrangeira devem ser aprimoradas.

\subsection{Atitudes que o gerente de marketing apresenta atualmente}

Além de possuir conhecimentos e habilidades relacionados à sua área de atuação, o gerente de marketing precisa ter atitudes compatíveis com suas atividades. Nesse sentido, segue a análise das atitudes que o gerente de marketing apresenta atualmente e das que deveria apresentar. $O$ gerente de marketing da empresa tem importantes atitudes, que fazem a diferença no desempenho de suas funções. $\mathrm{O}$ quadro 7 relaciona as dez principais desse gerente.

\begin{tabular}{|l|l|l|}
\hline \multicolumn{1}{|c|}{ Diretor de Operações } & \multicolumn{1}{c|}{ Gerente de Marketing } & \multicolumn{1}{c|}{ Subordinados do Gerente } \\
\hline Senso de responsabilidade & Senso de responsabilidade & Senso de responsabilidade \\
\hline Comunicação & Trabalhar em equipe & Noção de prioridades \\
\hline Flexibilidade & Flexibilidade & Comunicação \\
\hline Trabalhar em equipe & Análise & Trabalhar em equipe \\
\hline Noção de prioridades & Dinamismo & Organização \\
\hline Análise & Noção de prioridades & Análise \\
\hline Organização & Comunicação & Dinamismo \\
\hline Dinamismo & Organização & Flexibilidade \\
\hline Autocontrole & Autocontrole & Autocontrole \\
\hline Paciência & Paciência & Paciência \\
\hline
\end{tabular}

Quadro 7 - Atitudes que o gerente de marketing apresenta

Foi possível verificar que o gerente de marketing apresenta importantes atitudes para o eficiente desempenho de suas funções. Embora cada entrevistado tenha uma opinião diferente sobre o grau de importância das mesmas, é interessante ressaltar que houve unanimidade no primeiro aspecto citado, que foi o senso de responsabilidade. E nos dois últimos, que foram autocontrole e paciência; mostrando, assim, que o atual gerente de marketing é devidamente responsável nas suas atribuições, mas também cabe a oportunidade de exercitar sua paciência e seu autocontrole no ambiente de trabalho.

\subsection{Atitudes que o gerente de marketing deveria possuir}

O quadro 8 relaciona as principais atitudes que o gerente de marketing deveria apresentar, em ordem crescente de importância, segundo respostas dos entrevistados:

\begin{tabular}{|l|l|l|}
\hline \multicolumn{1}{|c|}{ Diretor de Operações } & \multicolumn{1}{c|}{ Gerente de Marketing } & \multicolumn{1}{c|}{ Subordinados do Gerente } \\
\hline Senso de responsabilidade & Senso de responsabilidade & Senso de responsabilidade \\
\hline Autocontrole & Trabalhar em equipe & Paciência \\
\hline Flexibilidade & Flexibilidade & Trabalhar em equipe \\
\hline Paciência & Organização & Autocontrole \\
\hline Comunicação & Dinamismo & Noção de prioridades \\
\hline Trabalhar em equipe & Noção de prioridades & Organização \\
\hline Organização & Comunicação & Dinamismo \\
\hline Dinamismo & Análise & Flexibilidade \\
\hline Noção de prioridades & Autocontrole & Análise \\
\hline
\end{tabular}




\begin{tabular}{|l|l|l|}
\hline \multicolumn{1}{|c|}{ Diretor de Operações } & \multicolumn{1}{|c|}{ Gerente de Marketing } & \multicolumn{1}{c|}{ Subordinados do Gerente } \\
\hline Análise & Paciência & Comunicação \\
\hline
\end{tabular}

Quadro 8 - Atitudes que o gerente de marketing deveria apresentar

É possível verificar as atitudes que o gerente de marketing da empresa deveria apresentar, variando de prioridade de um entrevistado para outro, mas cabe relevar que ambos, superior direto e subordinado, julgam autocontrole e paciência entre as principais atitudes para esse profissional. Tal fator não foi mencionado entre as principais atitudes pelo gerente, fato que deve ser observado por esse profissional, uma vez que as demais pessoas que trabalham com ele avaliam como um importante aspecto.

\section{CONSIDERAÇÕES E RECOMENDAÇÕES}

As pessoas atuam diretamente na execução das atividades e dos processos e são responsáveis pela implementação da gestão estratégica organizacional. A empresa, incentivando e auxiliando no desenvolvimento de competências de seus gestores e profissionais, caminha para a otimização de sua gestão estratégica e para a eficácia organizacional.

O profissional que apresente as competências compatíveis com sua área de atuação, juntamente com as estratégias bem definidas pela organização no seu planejamento estratégico, provavelmente alcançará os objetivos e resultados esperados pela empresa, bem como o seu crescimento profissional. No entanto, se suas competências não estiverem totalmente adequadas, a empresa pode desenvolver treinamentos, possibilitando que as funções sejam desempenhadas de maneira eficiente e eficaz, trazendo realização organizacional e pessoal. Dessa forma, fica fácil perceber que o desenvolvimento de competências pessoais é muito importante para a organização.

Pessoas capacitadas, qualificadas e dotadas de conhecimentos e comportamentos compatíveis com suas funções são o diferencial competitivo de qualquer empresa e a chave para seu sucesso. Os resultados demonstram que o gerente de marketing apresenta conhecimentos necessários para o eficiente desempenho de suas funções. Contudo, cabe ressaltar o alinhamento entre o diretor de operação e os subordinados do gerente de marketing sobre o grau de importância dos conhecimentos que esse gerente apresenta. Nesse mesmo aspecto, é evidente o alinhamento entre o gerente de marketing e seu superior sobre os conhecimentos que este cargo exige, ressaltando que o conhecimento em legislação tributária e em economia, que foram citados pela maioria dos entrevistados como conhecimentos que este gerente deveria apresentar, mas atualmente não apresenta. Essa questão deve ser levada em consideração, objetivando aprimorar os conhecimentos para exercer tal função.

Com relação às habilidades, verificou-se que o gerente de marketing apresenta importantes habilidades para o eficiente desempenho de suas funções. No entanto, os entrevistados têm diferentes opiniões sobre o grau de importância das mesmas. Conforme o diretor de operações e a maioria dos subordinados do gerente de marketing, as habilidades em língua estrangeira, finanças, negociação e tomada de decisão são relevantes para o desempenho desta função. Vale ressaltar que esses aspectos não foram citados pelos entrevistados como habilidades que o gerente apresenta.

Evidenciou-se que o gerente de marketing apresenta importantes atitudes para o eficiente desempenho de suas funções. Embora os entrevistados tenham opiniões divergentes sobre o grau de importância das mesmas, é interessante ressaltar que houve unanimidade no primeiro aspecto citado, que foi o senso de responsabilidade; e nos dois últimos, que foram 
autocontrole e paciência; mostrando, assim, que o atual gerente de marketing é devidamente responsável nas suas atribuições, mas também cabe a oportunidade de exercitar sua paciência e autocontrole no ambiente de trabalho. Esses fatores não foram mencionados entre as principais atitudes pelo gerente, fato que deve ser observado por tal profissional.

Concluiu-se que o gerente de marketing deveria apresentar as seguintes competências no departamento de marketing da empresa em questão:

\begin{tabular}{|l|l|l|}
\hline \multicolumn{1}{|c|}{ Conhecimentos } & \multicolumn{1}{|c|}{ Habilidades } & \multicolumn{1}{c|}{ Atitudes } \\
\hline Marketing e comunicação & Visão sistêmica & Senso de responsabilidade \\
Planejamento estratégico & Visão de mercado e negócio & Comunicação \\
Administração de empresas & Relacionamento interpessoal & Flexibilidade \\
Gestão estratégica & Flexibilidade & Trabalhar em equipe \\
Gestão de pessoas & Liderança & Noção de prioridades \\
Técnicas de negociação & Implementação de novas ideias & Análise \\
Técnicas de liderança & Persuasão & Organização \\
Contabilidade gerencial & Incentivo e pró-atividade & Dinamismo \\
Língua inglesa & Gestão de conflitos & Autocontrole \\
Sistemas de informação & Trabalhar sob pressão & Paciência \\
Legislação tributária & Língua estrangeira & \\
Economia & Finanças & \\
& Negociação & \\
\hline
\end{tabular}

Quadro 9 - Competências do gerente de marketing

Destarte, responde-se o objetivo geral do trabalho, que foi analisar as competências necessárias ao gerente de marketing para a otimização da gestão estratégica da organização. $O$ levantamento das competências esperadas do gerente de marketing pode auxiliar nas decisões sobre o desenvolvimento de competências gerencias compatíveis com esta área da empresa e, consequentemente, para o desenvolvimento pessoal e organizacional.

Evidenciou-se, ainda, que a organização é essencial para o desenvolvimento das competências gerenciais, pois identifica conhecimentos, habilidades e atitudes que são necessários para que as pessoas, que são fundamentais no processo de planejamento estratégico, sejam envolvidas e desenvolvam suas competências a fim de otimizar o processo de gestão estratégica na empresa.

Por fim, este trabalho teve sua relevância, tanto para a empresa como para o gerente de marketing, pois possibilitou a identificação de competências essenciais nessa área para o desenvolvimento da empresa de uma forma geral e, principalmente, o desenvolvimento e crescimento profissional do gerente de marketing.

\subsection{Recomendações}

Considerando-se os resultados do estudo, enumeram-se algumas recomendações mesmo não havendo interesse em esgotar o tema. Essas recomendações não seguem ordem de importância nem de prioridade, mas são algumas sugestões para estudos futuros.

- Analisar os demais diretores e gerentes da empresa, a fim de identificar as competências gerenciais desses profissionais de acordo com suas funções;

- Avaliar os resultados da implantação de um sistema de desenvolvimento das principais competências gerenciais identificadas nesse estudo; 
- Estudar a implementação de planos de desenvolvimento de competências gerenciais e gestão por competência;

- Estudar a possibilidade de refazer esta pesquisa em um número maior de empresas, possibilitando uma análise estatística dos resultados coletados, a fim de apresentar novos pareceres sobre o assunto;

- Incentivar a busca da melhoria nas condições de treinamento e desenvolvimento pessoal, inicialmente dos diretores, gerentes e, posteriormente, dos demais profissionais. 


\section{REFERÊNCIAS}

ALMEIDA, Martinho I. R. Manual de planejamento estratégico. São Paulo: Atlas, 2001.

ALMEIDA, M. de. Manual de planejamento estratégico: desenvolvimento de um plano estratégico com a utilização de planilhas Excel. 2.ed. São Paulo: Atlas, 2003.

ANSOFF, Igor H.; DECLERCK, Roger P.; HAYES, Robert L. Do planejamento estratégico à administração estratégica. São Paulo: Atlas, 1981.

ESTRADA, R. J. S..A. Eficiência e a Eficácia da Gestão Estratégica: do Planejamento Estratégico à Mudança Organizacional. In: Revista de Ciências da Administração. Florianópolis, v. 9, n. 19, p. 147-178, set-dez, 2007.

FLEURY, A.; FLEURY, M.T.L. As Estratégias Empresariais e Formação de Competências. 2e․ São Paulo: Atlas, 2001.

GRAMIGNA, M.R. O Modelo de Competências e Gestão dos Talentos. São Paulo: Makron Books, 2002.

HAMEL, Gary; PRAHALAD, C. K. The Core Competence of the Corporation. HBR (MayJune), 1990.

HAMEL, G.; PRAHALAD, C. K. Competing for future. Boston: Harvard Business School Press, 1994.

PARRY, S. B. The quest for competencies. In: Training, p. 48-56, July, 1996.

PORTER, M. E. Vantagem competitiva. Rio de Janeiro: Campus, 1991.

RABAGLIO, Maria Odete. Seleção por competências. 5aed. São Paulo: Educator, 2001.
RUSSELL REYNOLDS ASSOCIATES. The Sucessfull CMO. Disponível em http://www. russellreynolds.com/. Acesso em 2006.

SEBRAE. Serviço Brasileiro de Apoio às Micro e Pequenas Empresas. Disponível em:

http://www.sebrae.com.br/br/ parasuaempresa/conhecaomercado_803.asp. Acesso 10-09-2006.

ULRICH, D. Recursos humanos estratégicos. Traduzido por Bazán Tecnologia e Lingüística. São Paulo: Editora Futura, 2000. 
